http://jmscr.igmpublication.org/home/ ISSN (e)-2347-176x ISSN (p) 2455-0450 crossref DOI: https://dx.doi.org/10.18535/jmscr/v9i10.15

\title{
To Study the Effect of Vitamin C Supplementation on Brainstem Auditory Evoked Response in Diabetic Patients with Neuropathy
}

Authors

\section{Dr Shashikant Singh, Dr Shashi Sekhar Singh, Dr U.N Gupta, Dr P.K. Maheswari}

\section{Introduction}

Neuropathy is the most common complication and greatest source of morbidity and mortality in diabetes patients. It is estimated that the prevalence of neuropathy in diabetes patients is approximately 25\%. ${ }^{1}$ In diabetic neuropathy patients other part of neurological system is also affected such as autonomous system, sensory and motor pathways. Auditory Brainstem Response (ABR) audiometry.

First described by Jewett and Williston in 1971. There are seven waves traditionally designated with roman numerals from I to VII. Wave I and II represent activity in cochlear nerve, wave III in cochlear nucleus, wave IV in superior olivary complex, wave $\mathrm{V}$ which is biggest and most consistent represent activity in nuclei of lateral lemniscus while wave VI and VII in the inferior colliculus. $^{2}$ Interpretation of the BAEPs usually involves measuring the absolute latency of the three most prominent vertex positive peaks I, III, and $\mathrm{V}$, along with analysis of their relative interpeak latencies (IPLs), which may provide some anatomical localisation of lesions. Conduction through the eighth nerve and the caudal brainstem is represented by the I to III IPL, while the III to V IPL probably represents transmission through the rostral brainstem and midbrain. Neuropathy is the most frequent late complication of DM. So far most of the clinical and diagnostic studies on diabetic neuropathy have concerned only peripheral and autonomic nerve but recently with the refinement of evoked potential techniques detailed exploration of sensory pathway in central nervous system has been possible ${ }^{7}$. Brainstem auditory evoked potentials have obtained widespread clinical application in assessing neurologic and audiologic problems. ABR audiometry is considered an effective screening tool in the evaluation of suspected retrocochlear pathology. In general, ABR exhibits a sensitivity of over $90 \%$ and a specificity of approximately 70-90\%8 (Schmidt.et al., 2001).

Vitamin C also known as L-ascorbic acid, is a water-soluble vitamin that is naturally present in some foods, added to others, and available as a dietary supplement. Humans, unlike most animals, are unable to synthesize vitamin C endogenously, so it is an essential dietary component. Researcher have shown that vitamin $\mathrm{C}$ selectively restores the impaired endothelium-dependent vasodilation in the forearm resistance vessels of patients with insulin-dependent diabetes mellitus. These findings indicate that nitric oxide degradation by oxygen-derived free radicals contributes to abnormal vascular reactivity in humans with insulin-dependent diabetes mellitus. 
Scientists have shown that vitamin $\mathrm{C}$ is especially significant to diabetic neuropathy because research shows that most diabetics have a lack of Vitamin $\mathrm{C}$ as a result of their illness rather than diet. Those suffering from diabetic neuropathy have an elevated level of vitamin $\mathrm{C}$ which the body has already used known as reduced Vitamin C. This implies that neuropathy places an extra strain on the body's Vitamin C stores. As a result, it is important for diabetics to get sufficient levels of this vitamin through supplementation or diet.

\section{Aim}

To study the effect of vitamin $\mathrm{C}$ supplementation on blood glucose and brainstem auditory evoked potential in diabetic patients with neuropathy.

\section{Methodology}

A case control study was carried out among diabetic patients visiting Neurology division of a tertiary care centre. Total of 120 cases of vitamin $\mathrm{C}$ deficient diabetic patients with poly neuropathy were examined and investigated out of which 60 patients were cases and other 60 patients were control. Group I(Control) comprised of 60 vitamin $\mathrm{C}$ deficient diabetic patients with poly neuropathy receiving OHA or Insulin. Group II (Case) comprised of 60 vitamin $\mathrm{C}$ deficient diabetic patients with poly neuropathy receiving VitaminC $(1500 \mathrm{mg} /$ daily) orally along with OHA or Insulin. At the entry point of the study, the diabetic patients were given $1500 \mathrm{mg}$ of vitamin C daily for 6 months. Serum vitamin C concentration were estimated at 2, 4 and 6 months interval of time. Fasting blood glucose was done at first visit (at 0 weeks) and this was repeated subsequently at 2, 4 and 6 months respectively.

\section{Brainstem Evoked Potential}

ABR audiometry refers to an evoked potential generated by a brief click or tone pip transmitted from an acoustic transducer in the form of an insert earphone or headphone. The elicited waveform response is measured by surface electrodes typically placed at the vertex of the scalp and ear lobes. The amplitude (microvoltage) of the signal is averaged and charted against the time (millisecond), much like an EEG. The waveform peaks are labelled I-VII. These waveforms normally occur within a 10millisecond time period after a click stimulus presented at high intensities (70-90 dB normal hearing level [nHL] ${ }^{4}$

Recording one $\mathrm{cm}$ disc electrodes is filled with conducting jelly or paste are preferred. The electrode impedance should be kept below 5 kÙs. The active(positive) electrode is typically placed on either the high forehead $(\mathrm{Fz})$ or the vertex of the head $(\mathrm{Cz})$ and the ground electrode on the low forehead, the reference(negative) electrode can be placed over the mastoid process behind the ear. Filter band pass $100-3000 \mathrm{~Hz}$; Standard broadband click stimulation is used on the ear tested; Mono aural stimulation is used; The click intensity should be $60-70 \mathrm{~dB}$ above click perception threshold; The contra lateral ear receives masking noise of $30-$ to $40-\mathrm{dB}$ lesser intensity; The first $10 \mathrm{~ms}$ are averaged, and 24000 responses may be averaged; At least 2 separate trials should be performed (Leslie et al., 2002).Mainly waves that appear at the human scalp in the first $10 \mathrm{msec}$ after each stimulus (Picton et al.,1974). They are named according to their sequence in roman letters (from I to VII) (Chiappaet al., 1978) $^{48}$.

\section{Parameters measured are:}

1. Absolute latency and amplitude,

2. Interpeak latencies(IPL),

3. Amplitude ratio of wave $\mathrm{V} / \mathrm{I}$ or $\mathrm{IV}-\mathrm{V}$ complex

4. Inter ear interpeak differences.

\section{Normal value of different waves}

For evaluating the level of improvements in the Brainstem Evoked Potential, the type II Diabetic patients with neuropathy were divided into two groups:

Group-I: Control group, were not given any vitamin $\mathrm{C}$ supplementation. patients were of 
comparable ages were of normal weight for height, on usual diet. Renal and liver function test were normal.

Group-II: The study group, were given 1500 $\mathrm{mg} /$ day of vitamin $\mathrm{C}$ for 6 months.

BAEP always recorded with the same equipment using the stimulus either in the form of click or tone pip is transmitted to the ear via a transducer placed in the insert ear phone or head phone. Stimulation performed with a $25 \times 18 \mathrm{~cm}$ screen with black and white checker-board pattern, each square with $1.1 \mathrm{~cm}$ sides. . The response evaluate by active electrodes placed on either the high forehead $(\mathrm{Fz})$ or the vertex of the head $(\mathrm{Cz})$ and the ground electrode on the low forehead, the reference(negative) electrode can be placed over the mastoid process behind the ear.

\section{Statistical Analysis}

Mean, Standard Deviation (S.D.) were calculated for each parameter. Data before and after administration of vitamin $\mathrm{C}$ were compared for statistical analysis paired " $\mathrm{t}$ " test was performed and ' $p$ ' value were obtained for knowing the significance between different variables.

In Group I, 58.33\% of patients belong to the 51-60 age group. $23.33 \%$ belongs to $41-50$ age group and $18.33 \%$ belongs to $61-70$ age group of patients. No case was found in $>70$ age group. 9 males and 5 females were in the 41-50 age group. 29 males and 6 females were in 51-60 age group. 10 males and 1 female was in 61-70 age group. Out of 60, 48 Males $(80.00 \%)$ and 12 females (20\%) were present in group I.

In Group II- $51.6 \%$ belongs to 51-60 age group. $31.6 \%$ belongs to $41-50$ age and $16.6 \%$ belongs to $61-70$ age group of Diabetic patients. No case was found in $>70$ age group. 15 males and 4 females were in 41-50 age group. 21 males and 10 females were in 51-60 age group. 9 males and 1 females were in 61-70 age group. Out of 60, 45 males $(75 \%)$ and 15 females (25\%) were present in group II.

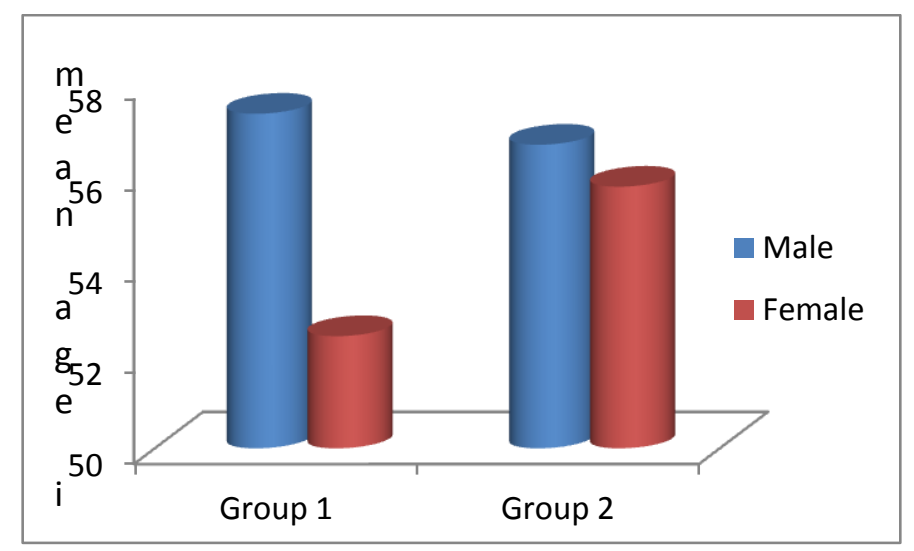

\begin{tabular}{|c|c|c|c|c|c|c|c|c|}
\hline & \multicolumn{4}{|c|}{ GROUP I $(n=60)$} & \multicolumn{4}{|c|}{ GROUP II $(n=60)$} \\
\hline & \multirow{2}{*}{$\begin{array}{c}\text { Before } \\
\text { treatme } \\
\text { nt }\end{array}$} & \multicolumn{3}{|c|}{ After Treatment } & \multirow{2}{*}{$\begin{array}{c}\text { Before } \\
\text { treatment }\end{array}$} & \multicolumn{3}{|c|}{ After Treatment } \\
\hline & & 2 months & 4 months & $\begin{array}{c}6 \text { mont } \\
\text { hs }\end{array}$ & & 2 months & 4 months & 6months \\
\hline Mean & 0.60 & 0.62 & 0.63 & 0.62 & 0.63 & 0.68 & 0.72 & 0.86 \\
\hline S.D & $\begin{array}{c}+/- \\
0.051\end{array}$ & $+/-0.042$ & $+/-0.060$ & $\begin{array}{c}+/- \\
0.046\end{array}$ & $+/-0.055$ & $+/-0.047$ & $+/-0.058$ & $+/-0.060$ \\
\hline S.E.M & 0.010 & 0.014 & 0.008 & 0.013 & 0.009 & 0.012 & 0.01 & 0.009 \\
\hline $\begin{array}{l}\% \text { Change Over } \\
\text { Baseline }\end{array}$ & & 39 & & & & & & \\
\hline $\mathrm{p}$ Value & & $\begin{array}{l}>0 . \\
\text { (I. }\end{array}$ & & & & & & \\
\hline
\end{tabular}


S. Vitamin C (mg/dl) Before and After Treatment.

Fasting Blood Glucose before and after treatment:

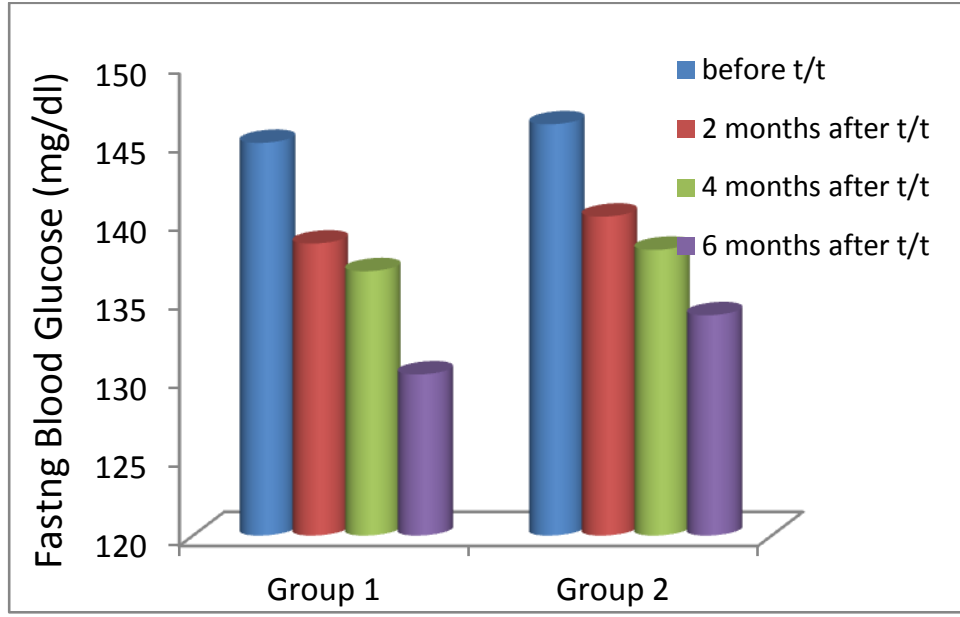

Latency (ms) of Waves In B.A.E.P of Left Ear before and after Treatment

\begin{tabular}{|c|c|c|c|c|c|c|c|c|}
\hline Wave & \multicolumn{4}{|c|}{ Value in (ms) in Study Group (60) } & \multicolumn{4}{|c|}{ Value in (ms) in Controls group (60) } \\
\hline & \multirow{2}{*}{$\begin{array}{c}\text { Before } \\
\text { treatment }\end{array}$} & \multicolumn{3}{|c|}{ After treatment } & \multirow{2}{*}{$\begin{array}{c}\begin{array}{c}\text { Before } \\
\text { treatment }\end{array} \\
\begin{array}{c}\text { At 1slt } \\
\text { visit }\end{array}\end{array}$} & \multicolumn{3}{|c|}{ After treatment } \\
\hline & & 2 months & 4 months & 6 months & & 2 months & 4 months & 6 months \\
\hline $\mathrm{I}$ & $1.94 \pm 0.10$ & $1.80 \pm 0.09$ & $1.70 \pm 0.08$ & $1.60 \pm 0.12$ & $1.84 \pm 0.14$ & $1.88 \pm 0.16$ & $1.84 \pm 0.17$ & ' $1.88 \pm 0.16$ \\
\hline III & $4.48 \pm 0.20$ & $4.10 \pm 0.22$ & $3.90 \pm 0.22$ & $3.76 \pm 0.16$ & $4.47 \pm 0.18$ & $4.42 \pm 0.20$ & $4.50 \pm 0.16$ & $4.38 \pm 1.8$ \\
\hline $\mathrm{V}$ & $6.60 \pm 0.25$ & $6.24 \pm 0.20$ & $5.82 \pm 0.32$ & $5.70 \pm 0.30$ & $6.49 \pm 0.31$ & $6.50 \pm 0.28$ & $6.52 \pm 0.29$ & $6.6 \pm 0.28$ \\
\hline I-III IPL & $2.53 \pm 0.30$ & $2.34 \pm 0.18$ & $2.20 \pm 0.24$ & $2.11 \pm 0.21$ & $2.56 \pm 0.32$ & $2.56 \pm 0.29$ & $2.54 \pm 0.32$ & $2.61 \pm 0.28$ \\
\hline III-V IPL & $2.36 \pm 0.25$ & $2.21 \pm 0.34$ & $2.16 \pm 0.28$ & $2.10 \pm 0.24$ & $2.51 \pm 0.25$ & $2.44 \pm 0.31$ & $2.46 \pm 0.26$ & $2.50 \pm 0.29$ \\
\hline I-V IPL & $4.61 \pm 0.30$ & $4.40 \pm 0.24$ & $4.23 \pm 0.26$ & $4.10 \pm 0.24$ & $4.40 \pm 0.21$ & $4.53 \pm 0.24$ & $4.59 \pm 0.25$ & $4.50 \pm 0.22$ \\
\hline
\end{tabular}

\section{Discussion}

Total 120 cases of diabetic neuropathy patients were subdivided into two groups, of 60 patients in each group. Group-I Control group were not given any Vitamin C supplementation. Group-II consists of study population who were given $1500 \mathrm{mg} /$ day vitamin $\mathrm{C}$ for 6 months.

Patients were distributed according to different age starting from $>40$ years and according to sex. In group I maximum number of patients $(n=35)$ were in 50-60 age years and in group II maximum number of patients $(n=31)$ were in age group 5060 years. In both group maximum number of patients were in 50-60 years age group.

In group I there were 48 male patients and 12 female patients (M:F ratio 4.0:1) and in group II there were 45 males and 15 females (M:F ratio $3.0: 1)$. In both group males are affected more than females. Similar findings were observed by $\mathrm{R}$ Pradeepa \& et.al. (2008).
Average age of males was $57.34+0.531$ years and of females was $52.46+0.561$ years in group I. In group II Average age of males was $56.66+0.624$ years and of females was $55.74+$ 1.587 years.

Mean duration of diabetes in group I was $20.83 \pm$ 0.76 as compared to $22.83 \pm 0.83$ in group II. Maximum no. of patients in both groups were having duration of diabetes between 11 to 15 years.

In our study, in group I family history of diabetes was present in $62 \%$ of cases and in group II family history was present in 54\% of cases. Vishwanathan M (1994) found prevalence (62\%) of diabetes in families of diabetic patients in Indian population.

Total 120 cases of diabetic neuropathy patients were subdivided into two groups.

Group-I: were not given any vitamin C supplementation. 
Group-II: the study population were given $1500 \mathrm{mg}$ of vitamin $\mathrm{C}$ per day for 6 months.

Serum vitamin C, Fasting Blood Glucose was measured before and after treatment at 2, 4 and 6 months. Latency of Brainstem Evoked Potential was investigated at above schedule.

The results of the present study are summarized below:

In Group I $-58.33 \%$ of patients belong to the 5160 age group. $23.33 \%$ belongs to $41-50$ age group and $18.33 \%$ belongs to $61-70$ age group of patients. No case was found in $>70$ age group. 9 males and 5 females were in the 41-50 age group. 29 males and 6 females were in 51-60 age group. 10 males and 1 female was in 61-70 age group. Out of 60, 48 Males (80 \%) and 12 females $(20 \%)$ were present in group I.

In Group II- $51.60 \%$ belongs to 51-60 age group. $31.6 \%$ belongs to $41-50$ age and $16.6 \%$ belongs to 61-70 age group of Diabetic patients. No case was found in $>70$ age group. 15 males and 4 females were in 41-50 age group. 21 males and 10 females were in 51-60 age group. 9 males and 1 females were in 61-70 age group. Out of 60, 45 males $(75 \%)$ and 15 females (15\%) were present in group II.

In Total- out of 120 diabetic patients 93 were males $(77.5 \%), 27$ were females $(22.5 \%)$

- In Both Group Patients were distributed according to different age starting from > 40 years and according to sex. In both group maximum number of patients were in 50-60 years age group.

- Average age of males was $57.34 \pm 0.531$ years and of females was $52.46 \pm .561$ years in group I. In group II Average age of males was $56.66 \pm 0.624$ years and of females was $55.74 \pm 1.587$ years. In group I Average age of total male and female were $55.23 \pm 0.457$ years and in group II were $56.10 \pm 0.576$ years.

- Mean duration of diabetes in group I was $20.83 \pm 0.76$ years as compared to $22.83 \pm 0.83$ years in group II.
In Group I; Mean Baseline value for S. vitamin C $(\mathrm{mg} / \mathrm{dl})$ is $0.60+/-0.051$ and after treatment values at 2 months is $0.63+/--.060,4$ months $0.63+/-0.060$, at 6 months $0.62+/-$ 0.046 respectively. In this group we observed that difference in $\mathrm{S}$. vitamin $\mathrm{C}(\mathrm{mg} / \mathrm{dl})$ values before and after 6 months of vitamin $\mathrm{C}(\mathrm{mg} / \mathrm{dl})$ supplementation was significant ( $\mathrm{P}$ value $>0.05$ )

In Group II; Mean Baseline value for S. vitamin C $(\mathrm{mg} / \mathrm{dl})$ is $0.63+/-0.055$ and after treatment values at 2 months is $0.68+/-0.047,4$ months $0.72+/-0.058$, at 6 months $0.86+/-0.060$ respectively. In this group there was highly significant $(\mathrm{P}$ value $<0.01)$ difference in $\mathrm{S}$. vitamin $\mathrm{C}(\mathrm{mg} / \mathrm{dl})$ between before and after 6 months of treatment.

In present study values for Mean fasting blood glucose level in group I before treatment (i.e. first visit) was $144.96+0.95 \mathrm{mg} / \mathrm{dl}$ as compared to $130.24+0.79 \mathrm{mg} / \mathrm{dl}$ values of after treatment. This difference was considered Significant between before and after treatment values for fasting blood glucose levels $(\mathrm{p}<0.01)$

In group II values for mean fasting blood glucose level before treatment (i.e., first visit) was $146.14 \pm 1.17 \mathrm{mg} / \mathrm{dl}$ as compared to $134.00 \pm 0.93$ $\mathrm{mg} / \mathrm{dl}$ values of fasting blood glucose after 6 months treatment. This Difference was also considered Significant.

In present study mean value for latency of left ear In group I before treatment (i.e. first visit) Mean value for latency of left ear was wave I:1.84 \pm 0.16 , wave III:4.47 \pm 0.18 , wave V: $6.49 \pm 0.31$, wave IIII IPL:2.56 \pm 0.32 , wave III-V IPL:2.51 \pm 0.25 , wave I-V IPL:4.40 \pm 0.21 compared to wave

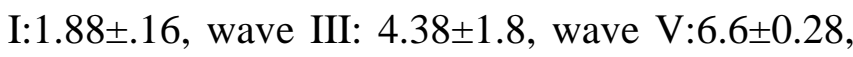
wave I-III IPL:2.61 \pm 0.28 , wave III-V IPL: $2.5 \pm 0.29$, wave I-V IPL:4.58 \pm 0.22 respectively after treatment (i.e after 6 months). This difference was Statistically Insignificant $(p>0.05)$.

In group II before treatment was wave I: $1.94 \pm 0.10$, wave III:4.48 \pm 0.20 , wave V:6.60 \pm 0.25 , wave I-III IPL:2.53 \pm 0.30 , wave IIIV IPL:2.36 \pm 0.25 , wave I-V IPL:4.61 \pm 0.30 , compared to wave I: $1.60 \pm 0.12$, wave 
III:3.76 \pm 0.16 , wave V:5.70 \pm 0.30 , wave I-III IPL:2.11 \pm 0.21 , wave III-V IPL: $2.10 \pm 0.24$, wave I-V IPL:4.10 \pm 0.24 respectively after 6 months of treatment. This Difference was considered significant $(\mathrm{p}<0.01)$.

\section{In present study mean value for right ear:}

In Group I before treatment (i.e. first visit) Mean value for amplitude of right ear was wave I:1.80 \pm 0.13 wave III:4.36 \pm 0.18 wave V:6.5 \pm 0.3 wave I-III IPL:2.5 \pm 0.31 wave III-V IPL:2.5 \pm 0.29 wave I-V IPL:4.6 \pm 0.22 compared to wave I:1.84 \pm 0.16 wave III : $4.26 \pm 1.7$ wave V:6.61 \pm 0.29 wave I-III IPL: $2.63 \pm 0.29$ wave III-V IPL: $2.50 \pm 0.30$ wave I-V IPL: $4.58 \pm 0.22$ respectively after 6 months of treatment. This difference was Statistically Insignificant ( $p>0.05$ ).

In Group II before treatment was wave I:1.78 \pm 0.13 , wave III: $4.40 \pm 0.22$, wave V:6.5 \pm 0.33 , wave I-III IPL:2.5 \pm 0.3 , wave III-V IPL:2.38 \pm 0.28 , wave I-V IPL: $4.4 \pm 0.38$ compared to wave I: $1.61 \pm 0.05$, wave III:3.75 \pm 0.20 , wave V: $5.78 \pm 0.34$, wave I-III IPL:2.1 \pm 0.27 , wave III-V IPL:2.34 \pm 0.22 , wave I-V IPL:4.2 \pm 0.25 respectively after 6 months of treatment. This Difference was considered significant $(p<0.05)$.

\section{Conclusion}

In Group I without vitamin C supplementation results of fasting blood glucose level were significant. In Group II Effect of vitamin C supplementation on fasting blood glucose were significant. Results for improvement in latency of BAER of both ears were significant in group 2 . Results were insignificant in group 1. Vitamin C supplementation helps to improve latency in patients of diabetic neuropathy.

\section{References}

1. Axelsson Garry, Johmpson Father, fagerberger et al; Diabetic Neuropathy: Etiology and Pathogenesis; Med , 1999;22:28-34.

2. Bayazit Y, Yilmaz M, Kepekçi Y, Mumbuç $\mathrm{S}$, Kanlikama $\mathrm{M}$ et al. Use of the auditory brainstem response testing in the clinical evaluation of the patients with diabetes mellitus. J Neurol Sci. 2000;181(1-2):2932.

3. Bayazit Y, Yilmaz M, Kepekçi Y, Mumbuç $\mathrm{S}$, Kanlikama $\mathrm{M}$ et al. Use of the auditory brainstem response testing in the clinical evaluation of the patients with diabetes mellitus. J Neurol Sci. 2000;181(1-2):29-32

4. Block G, Henson DE, Levine M. Vitamin C; a new look. Ann Intern Med 1991;114:90910

5. Chatterjee IB, Banerjee A. Estimation of dehyroascorbic acid in blood of diabetic patients. Anal Biochem 1979;98:368-74.

6. Chen MS, Hutchinson ML, Pecoraro RE, Lee WY, Labbe RF Hyperglycemia induced intracellular depletion of ascorbic acid in human mononuclear leukocytes. Diabetes 1983;32:1078-81.

7. Comi G.et al. Studies on central nervous system function in diabetes mellitus. J Indian Med Assoc. 2001;84:86-9.

8. Das T, Kundu S, Mazumdar AK, Mukhopadhyay SC. Studies on central nervous system function in diabetes mellitus. J Indian Med Assoc. 2001;84:869.

9. Durmus C, Yetiser S, Durmus O. Auditory brainstem evoked responses in insulin dependent (ID) and non insulin dependent (NID) diabetic subjects with normal hearing. Int J Audiol. 2004;43:29-33.

10. Dyck PJ, Karnes JL, Daube J, O'Brien P, Service FJ (1985) Clinical and neuropathologic criteria for the diagnosis and staging of diabetic polyneuropathy. Brain 108: 861-880

11. Dyck PJ, Karnes JL, Daube J, O'Brien P, Service FJ (1985) Clinical and neuropathologic criteria for the diagnosis and staging of diabetic polyneuropathy. Brain 108: 861-880

12. Fidele D, Martin A, Cardone $C$, et al. Impaired auditory Brain Stem Evoked 
response in diabetes mellitus.

Diabetes. 1999;33:1805-1089.

13. Frei B, England L, Ames BN. Ascorbate is an outstanding antioxidant in human blood plasma. Proc Natl Acad Sci USA 1989;86:6377-81

14. Harrison's principles of internal medicine 19e,ch. 459;1104-5

15. Imam M, Shehata OH. Subclinical central neuropathy in type 2 diabetes mellitus. Bull Alex Fac Med.2009;45:65-73.

16. Jennings PE, Chirico S, Jones AF, Lunec J, Barnett AH, Vitamin C metabolites and microangiopathy in diabetes mellitus. Diabetes Res 1987;6:151-4

17. Makasshima, Cristiane H Sales, L de Fatima, Campos Pedrosa et al: Pathogenesis of Diabetic Neuropathy 1998;25:554-562.

18. Maser RE, Steenkiste AR, Dorman JS et al. (1989) Epidemiological correlates of diabetic neuropathy: report from Pittsburgh epidemiology of diabetes complications study. Diabetes 38: 1456-1461

19. Maser RE, Steenkiste AR, Dorman JS et al. (1989) Epidemiological correlates of diabetic neuropathy: report from Pittsburgh epidemiology of diabetes complications study. Diabetes 38: 1456-1461

20. Pirart J (1979) Diabetes mellitus and its degenerative complications: a prospective study of 4400 patients observed between 1947 and 1973. Diabetes Care 1: 168-188

21. Rajendran S, Anandhalakshmi, Mythili B, Vishwanathan R. Evaluation of the incidence of sensorineural hearing loss in patients with type 2 diabetes mellitus. Int $\mathbf{J}$ Biol Med Res. 2011;2:982-7.

22. Retsky KL, Freeman MW, Frei B. Ascorbic acid oxidation product (s) protect human low density lipoprotein against atherogenic modification: anti-rather than prooxidant activity of vitamin $\mathrm{C}$ in the presence of transition metal ions. $\mathrm{J}$ Biol Chem 1993;268:1304-9.
23. Sharma R, Gupta SC, Tyagi I et al. Brain Stem Evoked Responses in patients with Diabetes Mellitus. Indian $J$ of Otolaryngology and Head and Neck Surgery 2000;52(3); 221- 229

24. Siddiqui SS, SA Hasan, Mohd. Aslam et al; Diabetes Mellitus and Neuropathy; J Neurology 2010, 23:45-57.

25. Sinclair AJ, Lunec J, Girling AJ, Barnett A. Modulators of free radical activity in diabetes mellitus: role of ascorbic acid. Free Radic Aging 1982;342-52.

26. Som S, Basu S, Mukherjee D, et al. Ascorbic acid metabolism in diabetes mellitus. Metabolism 1981;30-572-7.

27. SwakshyarSP,Dyck PJ, Kratz KM, Karnes JL, Litchy WJ, Klein R, Pach JM et al. The prevalence by staged severity of various types of diabetic neuropathy, in a population-based cohort: The Rochester Diabetic Neuropathy Study. Neurology 2010;43:17-24.

28. The DCCT Research Group (1988) Factors in the development of diabetic neuropathy. Diabetes 37: 476-481

29. The DCCT Research Group (1988) Factors in the development of diabetic neuropathy. Diabetes 37: 476-481

30. Toth et al, Brainstem auditory evoked potential examinations in diabetic patients, Scandinavian Audiology 2001; 30;156-159.

31. Virtanierni J, Laakso M, Nuutinen J, Karjalainens. Scott Brown's Otolaryngology. 6. Vol. 3. London: Butterworths; 1997. Quoted by Booth JB; p. 95.

32. Young et al. Central and peripheral conduction abnormalities in diabetes meliitus. Egypt J Neurol Psychiatry Neurosurg. 2005;42:209-21 